\title{
JOÃO ANTÓNIO FREDERICO FERRO E A INVASÃO FRANCESA DE 1809: $O$ saque dos conos
}

Francisco Topa

\begin{abstract}
Resumo
$O$ artigo estuda um poema herói-cómico de teor erótico, intitulado $O$ saque dos conos. Da autoria do português João António Frederico Ferro, tem por tema as violações cometidas pelas tropas francesas aquando da sua entrada na cidade do Porto, em 1809. Entre as várias edições da obra - que dispõe também de versões manuscritas - há uma brasileira, impressa no Rio de Janeiro, em 1836.
\end{abstract}

Palavras-chave: Poema herói-cómico; erotismo; João António Frederico Ferro.

\begin{abstract}
The article studies a mock-heroic narrative poem with erotic content entitled $O$ saque dos conos. Written by the Portuguese João António Frederico Ferro, has for subject the violations committed by French troops on its entry in the city of Porto in 1809. Among the various editions of the work - which also has manuscripts versions - there's a Brazilian one, printed in Rio de Janeiro in 1836.
\end{abstract}

Keywords: mock-heroic narrative poem; eroticism; João António Frederico Ferro.

Segundo Inocêncio Francisco da Silva (III, 1859, p. 289), João António Frederico Ferro seria natural do Porto, tendo nascido provavelmente entre 1780 e 1785 . Formado em Direito pela Universidade de Coimbra, seria um defensor dos «principios da monarchia absoluta, e mais tarde [d]os contestados direitos do sr. D. Miguel ao throno de Portugal.». Teria escrito:

- Odes recitadas nas tres noutes em que o Senado da Camara da cidade do Porto solemnisou a feliz restauração de Portugal, Coimbra, na Impr. da Universidade, 1808;

- Ode ao Vice-reitor da Universidade, e aos portuguezes, por occasião da restauração de Portugal, ibid., na mesma Impr., 1808.

Acrescenta o autor do Diccionario bibliographico portuguez:

Atrribue-se-lhe ainda a composição de um poema obsceno, impresso clandestinamente por mais de uma vez, que é assás conhecido, e do qual foi tristissimo assumpto a invasão dos francezes no Porto em 1809, comandados por Soult.

Refere igualmente Inocêncio que «me affirmam ser d'elle o seguinte opusculo, Cruzeiro do Sul (AC): UFAC/CEL (Campus Floresta), 2013 


\section{ANTHESIS: Revista de Letras e Educação da Amazônia Sul-Ocidental, ano 02, no 04}

publicado anonymo:

307) Desafogos poeticos de um corcunda portuense no tempo da Constituição, Lisboa, na Offic. da Horrorosa Conspiração, 1823. 4. ${ }^{\circ}{ }^{\prime}$ (SILVA, III, 1859, p. 289-290).

No tomo X, terceiro do suplemento (SILVA, X, 1883, p. 154), acrescenta-se mais um poema:

- «Ode ao il. ${ }^{\text {mo }}$ e ex. ${ }^{\text {mo }}$ sr. Manuel Paes de Aragão Trigoso, etc. Sem logar da impressão, mas parece ter sido impressa em Coimbra, como o foram outras poesias da mesma epocha. A dedicatoria é datada de 26 de agosto de 1808.»

No tomo seguinte (SILVA, XI, 1884, p. 275), junta-se um último texto:

- «Ode a João Manuel de Mariz Sarmento, capitão de artilheria do real exercito portuguez e restaurador da cidade do Porto. Offerecida ao principe regente por um vassalo fiel. Corunha, na imp. de D. Francisco Candido Perez Prieto. Sem data. 4. ${ }^{\circ}$ de 7 pag.».

Como também diz Inocêncio, Frederico Ferro foi redator do jornal político Correio do Porto, que se publicou entre 1820 e 1834 . Embora anónimos, há vários poemas aí inseridos que talvez sejam da sua autoria. É o caso da ode que vem no número de 24 de agosto de 1821 - um número impresso a vermelho, numa forma de assinalar a efeméride - e que voltaria a ser publicada no mesmo dia do ano seguinte. Entre outros aspetos político-ideológicos interessantes, aí podemos ver uma proclamação de fé na Razão e nos seus efeitos sobre a superstição:

A luminosa Estrella

Da Celeste Razão, que envergonhada

Entre sombras vagava, appar'ceo bella

Em Tua Madrugada!

O Horisonte ostentou nova belleza;

Sôou no Douro a voz da Natureza!

Entre suave canto,

Em Carro triunfal, candida veste,

A saúdar-Te baixou do Olimpo sancto

Religião Celeste;

De seu lume affastando sempre puro

Da vil Superstição o bafo impuro!

A relação de obras apresentada no volume II do Dicionário bibliográphico da Guerra Peninsular, de Cristovam Ayres de Magalhães Sepúlveda (1926, p. 34), não apresenta novidades, excetuando a menção explícita do texto que nos interessa:

- «Saque dos c... ou Relação do que aconteceu às Moças do Porto, pela entrada do 
Exercito Francez, em março de 1808, (9?). Poema epico dedicado à immortal Catharina...

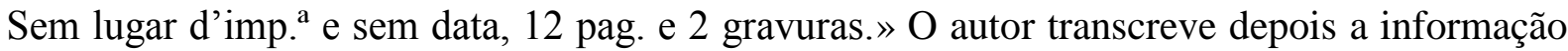
de Inocêncio, de acordo com a qual o autor seria Frederico Ferro.

Para além dessa, que não consegui localizar, e de uma outra de que falarei mais à frente, há uma edição feita no Rio de Janeiro, em 1836, sem indicação de tipografia ou casa editora: Saque dos Conos ou Relação do que aconteceu ás Moças do Porto Pela entrada do Exercito Francez, em Março de $1808^{1}$; Pelo Senhor F.... Esta edição tem a particularidade de apresentar um prólogo cujo interesse resulta da circunstância de se tratar do primeiro - e até agora único, tanto quanto julgo saber - texto crítico sobre o poema erótico de Frederico Ferro. Percebe-se contudo de imediato que o anónimo editor tenderá a preferir a preterição e as generalidades à crítica precisa:

Como de ordinario não se imprime obra alguma, sem que o seu competente prologo a preceda, sou obrigado a prevenir o publico, que em quanto ao auctor do Saque, eu apenas sei, que pertence ao Senhor F. do Porto, e até nem sei mais, que a letra inicial de seu sobrenome. Em tal caso sou obrigado a supprir em parte a esta especie de ornato, ou condecoração de imprensa.

Depois disto vem um comentário genérico sobre o estilo e «os bons rasgos de moral»:

(...) achei que o Senhor F.... faz muitos bons versos pois que nelles se acha cadencia, força e expressão \&c., e preferirei esta obra á Martinhada por ser menos hyperbolica, e haver nella factos muito authenticos; tem bellos rasgos de imaginação, as comparaçoens magnificas (...).

Pessoa alguma das que estiverem ao facto deste Poema, deixarão de conhcer o bello espirito do auctor neste genero, e a sua bella propensão; mas ninguem lhe poderá negar, no meio de suas gaiatisses os bons rasgos de moral, que muito a tempo desenvolve.

O prólogo termina com a defesa da utilidade deste tipo de literatura, através de um argumento duplo:

(...) não pode estimar-se o bem, sem o conhecimento do mal, e que o decente seria desconhecido, se o indecente não existisse, e emfim, que nada é capaz de fazer perpetuar no homem faltas mais graves, do que seja a ignorancia.

Há muitas obras serias, mas tambem as á joco-serias, e umas dão merecimento as outras; á muitas decentes, e as indecentes são igualmente uteis, finalmente não á obra alguma, que não tenha o seu merito.

Como seria de esperar de uma obra deste tipo, há várias versões manuscritas de $O$ Saque dos Conos. Embora não tenha feito nenhuma pesquisa exaustiva a propósito, localizei

\footnotetext{
${ }^{1}$ Na verdade, 1809 .
}

Cruzeiro do Sul (AC): UFAC/CEL (Campus Floresta), 2013 


\section{ANTHESIS: Revista de Letras e Educação da Amazônia Sul-Ocidental, ano 02, no 04}

três, em bibliotecas diferentes:

- Arquivo Distrital de Braga, Ms. 96 (atribuído a «J. A. Fr. Ferro»);

- Biblioteca Pública Municipal do Porto, Ms. 1951, em que há uma nota dizendo que se trata de cópia de um impresso (com muita probabilidade a edição de 1836, do Rio de Janeiro);

- Library of Congress, Portuguese Manuscripts, Ms. 127.

A estas três versões - nenhuma datada e todas apógrafas - somam-se pelo menos três edições: a que foi referida por Magalhães Sepúlveda, sem data nem lugar de edição; a do Rio de Janeiro, de $1836^{2}$; uma outra, sem data, alegadamente impressa em Alger, na Typographie et Lythographie A. Bouyer, com 108 pp. ${ }^{3}$. Para além de outras particularidades, esta última indica explicitamente o nome do autor: J. A. Frederico Ferro. Esse dado faz supor que ela seja posterior à do Rio de Janeiro, dado que Inocêncio, em 1859, mostra não a conhecer: caso contrário, não daria como dubitada a autoria de Ferro. Confrontando os testemunhos, percebem-se facilmente os erros de cada um e a consequente necessidade de restituir criticamente o texto. Não é esse contudo o propósito deste artigo, com o qual pretendo apenas chamar a atenção para uma forma diferente de encarar a invasão francesa de 1809 , cumprindo um duplo objectivo: apresentar um autor que, sendo obviamente um poeta menor da fase epigonal do nosso neoclassicismo, tem algum interesse, sobretudo pelas suas posições político-ideológicas; discutir um dos poucos textos da nossa pobre literatura erótica - ou pornográfica, ou obscena, discussão um tanto estéril em que não entrarei -, mais raro ainda devido à opção pelo género épico e por um tema que diríamos impossível.

Embora apresente numerosas gralhas e vários erros claros, seguirei a edição de Alger, que é a mais interessante: pela indicação explícita do autor; pela estratégia de dissimulação dos elementos tipográficos, um procedimento comum neste género editorial; pelas ilustrações obscenas; pela inclusão de outros textos, aparentemente do mesmo autor.

\footnotetext{
${ }^{2}$ Existente na Biblioteca Pública Municipal do Porto, com a cota P-D-116.

${ }^{3}$ Há um exemplar na Biblioteca Nacional de Lisboa, com a cota L. 75003 P.
} 


\section{O SAOULE DOS CONOS}

POEMA

DEDICADO A'MEMORIA DA IMMORTAL

\section{CATHARINA}

POR

J. A. FREDERICO FERRO

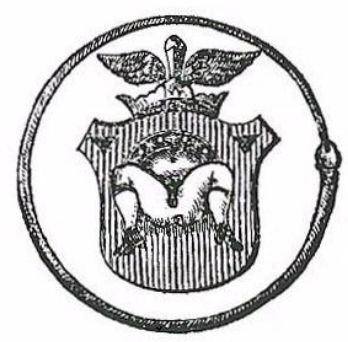

ALGER

Typographie et Ly thographie A. Bourer, Rue Bab-Azoun

Na verdade, no que diz respeito a $O$ saque dos conos, as ilustrações são apenas três: uma gravura antecedendo o texto, no anterrosto, em posição vertical, o que obriga o leitor a virar o livro:

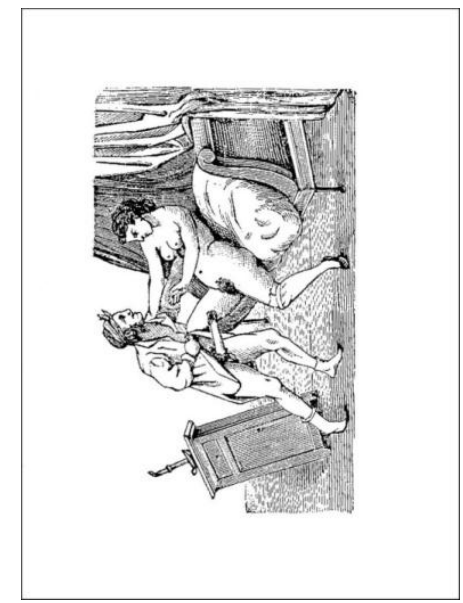


uma vinheta na folha de rosto, numa subversão paródica dos símbolos nacionais:

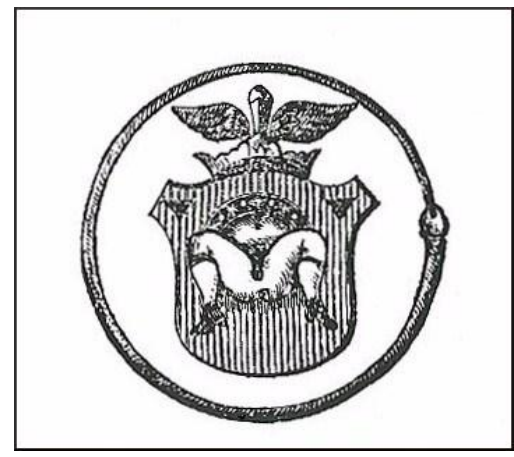

outra no final do poema (p. 16):

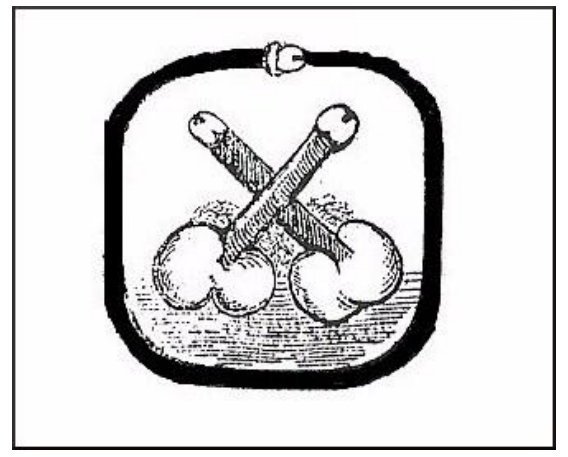

em todas ressaltando a dimensão dos falos, como é habitual no género.

A edição inclui também três outros textos, que deverão ser tidos como pertencendo a Frederico Ferro, uma vez que nada é dito em contrário: o «Regimento para conhecer se as putas tem gallico», uma letrilha em quintilhas de redondilha menor, seguidas de um quebrado de três sílabas; «Documentos para os novatos não pagarem mais do que devem» (subentendase: no comércio carnal), outra letrilha de idêntica forma; um texto em prosa, bem mais longo, intitulado «Os Amores galanteios e passatempos das actrizes ou Confissões curiosas e divertidas dessas senhoras, recopiladas da Grande Opera de Paris, e agora traduzida (sic) em portuguez por $* * *$ ». Há ilustrações em dois destes textos: uma vinheta no final do primeiro (p. 21): 


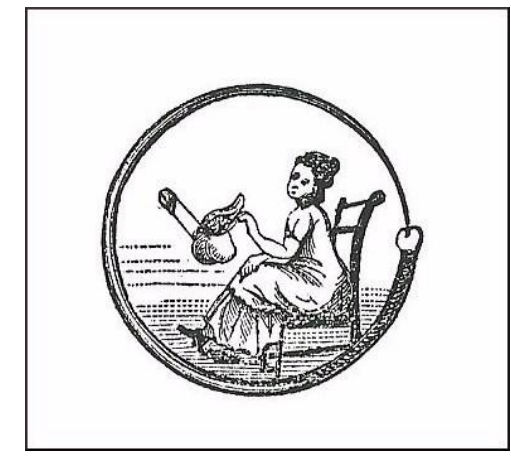

uma gravura sensivelmente a meio do último (antes da p. 81), mais uma vez em posição vertical:

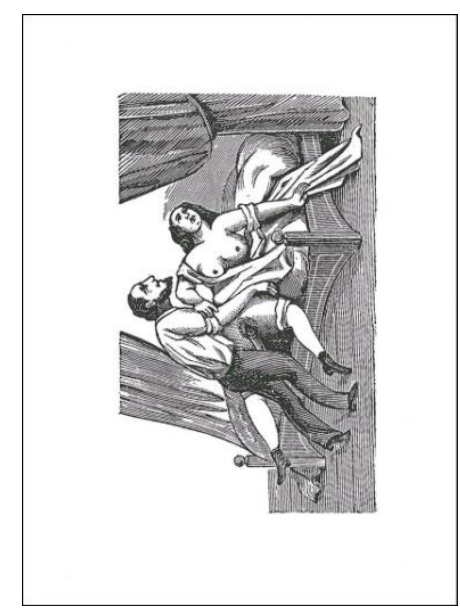

e outra vinheta no final do mesmo texto, que coincide com o final da obra (p. 108), agora com uma legenda que se lê da direita para a esquerda:

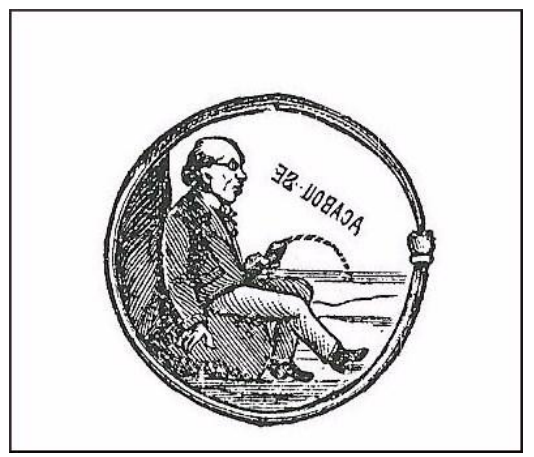

Feita esta breve apresentação do livro na edição de Alger, passarei então a $O$ Saque dos Conos, que, como se depreende do título e também do subtítulo de outras edições («Relação do que aconteceu às Moças do Porto, pela entrada do Exercito Francez, em março de 1808»), se propõe narrar, em estilo épico - como é característico do chamado poema heróicómico -, as violações cometidas pelas tropas francesas. Trata-se de um poema de fôlego 


\section{ANTHESIS: Revista de Letras e Educação da Amazônia Sul-Ocidental, ano 02, no 04}

curto, constituído por dois únicos cantos, num total de 286 versos decassilábicos, maioritariamente heroicos, de estrofação irregular e rima emparelhada. O desenvolvimento do argumento revela também, como rapidamente teremos oportunidade de ver, o fôlego curto do autor: se, por um lado, devemos reconhecer a ousadia e o ineditismo - pelo menos em contexto nacional - do tema, por outro não podemos deixar de lamentar o seu empobrecimento com a restrição ao mundo conventual e com o aparente propósito moralizador de alertar os pais para os riscos que correm com as filhas. Apesar desta nota anticlerical (ou anticonventual) - que aliás parece contrariar a verdade histórica ${ }^{4}$-, Frederico Ferro está bem longe dos libertinos franceses dos séculos XVII e XVIII, embora o seu texto não mereça o esquecimento em que acabou por cair.

O primeiro sinal da cedência ao lugar-comum vem na epígrafe, retirada de um conhecido soneto que andou atribuído a Bocage ${ }^{5}$ e que sublinha a dedicatória à «Immortal Catharina»-Catarina II da Rússia, conhecida pelos seus inúmeros amantes:

Essa da Rússia imperatriz famosa

Que inda a pouco morreu (diz a Gazeta)

Entre mil porras expirou vaidosa.

Um pouco mais interessante é o modo como o autor atualiza a estrutura do poema épico, abrindo com a invocação, que ocupa os dois primeiros versos:

Ainda uma só vez, Musa te rogo,

A meu extremo assumpto inspira fogo:

Há duas expressões curiosas nesta passagem: fogo, um termo que no contexto de um poema erótico é equívoco, dado o seu sentido duplo; extremo assumpto, que parece evidenciar a consciência transgressora do tema.

Temos depois a proposição, em que a narrativa é apresenta como «caso novo» (v. 3) e «extranho assumpto» (v. 6), e uma espécie de invocação - mais declaradamente paródica - às «dos Guindaes nymphas tunantes» (v. 7), que «a cada canto» fazem «sementeira» «Da mais cruel, podre galliqueira;» (v. 10). Um tanto previsível, este tópico das doenças venéreas justifica-se aqui pela possibilidade de introduzir o tema do francês. Note-se também o efeito estilístico da animização metonímica e da espécie de oxímoro desta passagem:

\footnotetext{
${ }^{4}$ De acordo com testemunhos contemporâneos, os conventos terão colaborado na resistência ao invasor. Cf. LIMA, s/d, p. 49.

${ }^{5}$ Começado pelo verso «Não lamentes, ó Nise, o teu estado» e hoje considerado da autoria provável de João Vicente Pimentel Maldonado.
}

Cruzeiro do Sul (AC): UFAC/CEL (Campus Floresta), 2013 
Desta sorte obrigando as pobres picas

A viagem fazer pelas boticas,

Na mão levando, em vez de passaporte,

As receitas, que dão á bolsa morte: (vv. 11-14)

A narração começa com a referência à fuga da população de Braga para o Porto e ao contraste entre o terror do povo e a alegria das moças e, em particular, das freiras:

Quando tudo era horror, espanto tudo,

Para as moças chegava um novo entrudo;

$\mathrm{E}$ as freiras nos conventos com tal nova

Aos já defuntos virgos dando escova,

Saltavam de prazer, prevendo rotos

Os que a força fizeram sacros votos,

Insólito prazer banhava a todas,

Só na lembrança das futuras fodas. (vv. 23-30)

Mantendo o registo humorístico, o narrador põe depois a ridículo a preocupação dos pais com a honra das filhas:

Todos tentam fugir, mas, mais se acendem

Os pais, que pôr a salva (sic) só pretendem

Virgo apparente, a quem tirára a vida

Com a ponta do dedo mão suicida.

Ou a quem, bem que a furto, algum supapo

Com a trompa já deu grosso marzapo;

Porque a foda que é dada ás escondidas

Sempre conserva o virgo ás mais fodidas. (vv. 35-42)

Um pouco mais à frente, a sátira estende-se aos noivos, numa aparente alusão à obra de João de Barros, Espelho de casados:

Oh vós, que ides casar, por meu conselho

Vinde, vende (sic) mirar-vos neste espelho! (vv. 53-54)

Num registo que se aproxima do poema herói-cómico, O Saque dos conos revela-se assim mais obsceno do que erótico ou pornográfico. O discurso direto - das moças ansiosas pela chegada dos franceses, das freiras e da Abadessa, esta também apresentada em monólogo com o seu «parrameiro» - assegura a vivacidade do relato, em que podemos encontrar hipérboles curiosas:

O allemão caralho corpulento,

Capaz té de foder o pensamento; (vv. 69-70)

ou um uso inesperado do aforismo: 
Não é preciso ir fóra buscar brasa,

Quando póde vir ter o lume a casa. (vv. 71-72)

O canto II abre com uma invocação a Calíope, a quem o narrador pede que lhe ensine «O trabalho das fodas na officina;» (v. 2), seguindo-se a narração das investidas sexuais das tropas francesas, que não terão encontrado nenhuma virgem:

Em virgos não fallemos nesta empreza,

Que destes não provou porra franceza; (vv. 7-8).

A par de metáforas e imagens interessantes:

Sendo a porra imperial p'ra [a]vós e tias

O rei Sebastião das prophecias! (vv. 29-30)

E soldado francez, que moça monta

É potente pardal, fode sem conta. (vv. 47-48)

surge frequentemente o discurso hiperbólico, sublinhando as façanhas francesas e o prazer causado nas destinatárias. Vejamos um exemplo do primeiro tipo:

Entre ellas reluzia um grã mazarpo,

Que de certo era porra de Priapo;

Fazia o seu minguante no joelho,

E o crescente o levava além do artelho,

De sorte que essa porra, que as fodengas

De Cascaes iam dar là nas Berlengas,

Em competencia d'este bom pepino

Parecia-me minhoca de menino:

Tão potente da foda nos trabalhos

Que na força igualava a cem caralhos,

Capaz de meia hora foder todas,

Pois só de um talho dava trezes fodas!

Ninguém há, que não queira o membro eterno,

Que é badalo de sino lá no inferno; (vv. 61-72)

Quanto ao prazer das freiras, sirva de exemplo a seguinte passagem, relativa à abadessa:

E tanto a tal fodenga saborea,

Que a vir-se esteve mais de hora e meia: (vv. 129-130)

Inicialmente esquecida, a madre só recebe atenção depois de dirigir uma longa súplica «ao gran caralho» (v. 92), no decurso da qual alude a algumas formas de obtenção de prazer 
que, para o leitor contemporâneo, constituem um curioso apontamento sobre os costumes da época:

Em vez de porra já usei de tripa,

Com que a luxúria o fogo dissipa. (vv. 101-102)

Estraguei bom proveito neste estudo

Seis ou sete caralhos de velludo, (vv. 107-108)

O poema termina com uma espécie de moralidade, dirigida aos pais, numa aparente justificação do tom anticlerical (ou anticonventual):

Pais vigilantes, que dobraes cautellas

Por sempre conservar filhas donzellas,

E vos outros, que sò por frioleiras,

Á força ides metter as filhas freiras,

Esta lição vos sirva de pressagio,

Que póde ainda chegar outro naufragio. (vv. 147-152)

Concluindo, creio que nem o texto nem o autor merecem o esquecimento a que têm estado votados e que se justifica, portanto um estudo mais demorado. Não sendo - ou não parecendo ser - $O$ saque dos conos um desses livros que se leem com uma só mão, para retomar a expressão de Jean-Marie Goulemot (2000), importa tentar perceber, por exemplo, o alcance da provocação quase nonsensical que resulta da forma com Frederico Ferro alude ao desastre da Ponte das Barcas: «Apenas escaparam com bem magoa / As que o Douro fodeu debaixo d'agua.» (vv. 51-52). Esperemos que esta breve apresentação represente um primeiro passo nesse sentido.

\section{Referências Bibliográficas}

GOULEMOT, J.-M. Esses livros que se lêem com uma só mão: leitura e leitores de livros pornográficos no século XVII. São Paulo: Discurso Editorial, 2000.

LIMA, D. P. Os Franceses no Porto, 1807-1808. Diário de uma testemunha presencial, anotado e precedido de uma introdução. Vol. II. Porto: Gabinete de História da Cidade, s/d.

SEPÚlVEDA, C. A. M. Dicionário bibliográphico da Guerra Peninsular. Coimbra: Imprensa da Universidade, 1926. 
ANTHESIS: Revista de Letras e Educação da Amazônia Sul-Ocidental, ano 02, no 04

SILVA, I. F. Diccionario bibliographico portuguez. Vol. III, X e XI. Lisboa: Imprensa Nacional, 1859, 1883 e 1884. 